\title{
SYSTEM ANTHROPOLOGICAL PSYCHOLOGY: METHODOLOGICAL FOUNDATIONS
}

\author{
Eduard V. Galazhinsky, \\ Vitaliy Y. Klochko, \\ Tomsk State University \\ Tomsk, Russia
}

The article considers methodological foundations of the system anthropological psychology (SAP) as a scientific branch developed by a well-represented group of Siberian scientists. SAP is a theory based on axiomatics of cultural-historical psychology of L.S. Vygotsky and transspective analysis as a specially developed means to define the tendencies of science developing as a self-organizing system. Transspective analysis has revealed regularities in a constantly growing complexity of professional-psychological thinking along the course of emergence of scientific cognition. It has proved that the field of modern psychology is shaped by theories constructed with ideation of different grades of complexity. The concept "dynamics of the paradigm of science" is introduced; it allows transitions to be acknowledged from ordinary-binary logic characteristics of the classical science to a binary-ternary logic, adequate to non-classical science and then to a ternary-multidimensional logic, which is now at the stage of emergence. The latter is employed in SAP construction. It involves the following basic methodological principles: the principle of directed (selective) interaction and the principle of generative effect of selective interaction. The concept of "complimentary interaction" applied in natural as well as humanitarian sciences is reconsidered in the context of psychology. The conclusion is made that the principle of selectivity and directedness of interaction is relevant to the whole Universe embracing all kinds of systems including the living ones. Different levels of matter organization representing semantic structures of various complexity use one and the same principle of meaning making through which the Universe ensures its sustainability as a self-developing phenomenon. This methodology provides an explanation for nature and stages of emergence of multidimensional life space of an individual, which comes as a foundation for generation of such features of consciousness as its system character and sensibility.

Keywords: paradigmal dynamics of science, self-development, self-organization, selective interaction, complementarity, one-dimensionality, binarity, ternarity, multi-dimensionality. 
The scientific field, which we have generated, and which is being actively developed by our disciples and followers, is defined as "system anthropological psychology" (SAP). It represents a phenomenon rather difficult for understanding. This makes the complex of methodological and theoretical ideas that lie at its foundation not so easily acceptable among the scientific community. The problem is that the framework of a new theory was initially constructed as a continuation of cultural-historical psychology, which foundation was established by L.S. Vygotsky and his followers. However, we attempted a bit more than mere adaptation of the original methodological basis of culturalhistorical psychology to modern realities of developing science; to a certain extent, we endeavored to anticipate and foresee a certain state of the scientific area, which will be characteristic of science in its nearest and distant future.

In other words, we relied upon the results of checking the objective tendencies of science development obtained through the specially elaborated method, which used to be called a historical system-based approach, and which we now prefer to define through such concepts as "transspective approach", "transspective analysis" (Klochko, 2005). Addressing the tendencies of science development proved to be productive, as it not only allowed us to observe the streamline of psychological cognition from a new perspective (as a process of science selfdevelopment), it also contributed an idea, which scientific community takes slow to embrace. It was the idea of regular growth of complexity of professional-psychological thinking along the course of emergence of scientific cognition. Hence, it was an assertion that the field of modern psychology is shaped by theories constructed with ideation of different grades of complexity. It meant implicitly that any direct integration of theories by their projection onto the current state of science was hardly possible, since the theories themselves differ in grades of complexity employed by their creators.

Representing science as a self-developing system we, to remain consistent, must as well regard theories constituting science as elements of the whole developing body. Whereupon the image of science "growing from within" in the process of putting forward and solution of cognitive brain twisters (T. Kuhn) transforms into the image of science existing in continuous exchange of information with its environment which involves culture in a broad sense of the word including other sciences, 
philosophy, religious studies etc. The source of (self-)development of science is associated nowadays with the process of cross-fertilization "mutual fertilization" (L. von Bertalanffy) of various scientific disciplines in the process of intrasystemic and intersystemic interactions.

The "mystery" of exchange is that it is undoubtedly an interaction, but it is a directed and selective interaction. It might be rather hard to comprehend and accept such a conclusion: psychologists got used to regard activity, action, influence even a counteraction as directed processes, but not an interaction. Not a very long time ago it was easier for us to accept the thesis that a single act of reflection is subjected to two different logics: reflection follows the logic of interaction, and its selectivity is submitted to the logic of activity.

It is not easy to recognize interaction of open systems with the environment as selective and directed. To do this it is necessary to acknowledge that the relation of a system to its environment is somehow involved in the act of interaction and that the very inclusion of relation into the core of interaction does attach directed and selective character to interaction. However, this particular notion is crucial for the theory of psychological systems (TPS) (Klochko, 1991), on the methodological basis of which system anthropological psychology is being established by the efforts of Siberian psychologists. Let us consider this principle in greater detail.

\section{The Principle of Selectivity and Directedness of Interaction as a Basal Principle of SAP}

In a broad sense this principle can be applied to any open system. It may embrace living systems studied by humanitarian sciences (these include an individual, science etc.), and those systems that are regarded by natural sciences. It can be asserted that all open systems are able to discern in a neutral environment something that has an actual meaning for them, that is, a direct relevance for current (here and now) state of a system. They do not linger waiting for something relevant here and now to "materialize" from the outside by accident or, which is almost the same, in the process of random handling of all existing options. Developing through exchange with the environment, they have acquired in this evolution their own means of selection. The principle of their selectivity (with all incommensurable complexity) is identical in the following. 
Open systems are able to project their expectation onto environment and thus, distort it through their presence in it in such a way that only something apt to meet the expectation, that is, something making sense, can resonate in response to this demand addressed to the environment. Electric fields surrounding a charged particle and fields of meaning recognized by a human being, all these systems work on this principle. If this is true, then there is an opportunity to reach a common foundation, which brings together natural-scientific and humanitarian thinking, and such 'reconciliation' is a constituent part of a more penetrating task involving a synthesis of two habits of thought within the construction of a holistic picture of the world. This still observed gap between the two modes of thinking crucially restricts the development of scientific knowledge, leaving little hope for creation of an integral self-coordinated scientific picture of reality.

Positive discourse in scientific area is strictly limited when the dialogue strives through conceptual partitions raised by peculiarities of apprehension, description and understanding of phenomena intrinsic to each line of thought. Modes of thinking in their advanced forms do not recognize each other as complementary, i.e. as mutually supplementary. As V.S. Bibler points out, complementarity of alternative definitions turned out to be "almost beyond comprehension" for the mind, brought up in traditions of classical science (Bibler, 1991). While now (provided for the experience in application of the non-classical paradigm) yet another, even more complicated idea seems to become mind-boggling. As once transition to non-classical ideals of rationality brought the acknowledgement of complementary interaction (from Latin "complementum" - addition), today assimilation of the ideals of post-non-classical rationality drives us to admit the existence of complimentary interactions (from French "compliment").

Complementarity, according to L. Gumilev, who used both terms, is the act of understanding, which goes beyond the limits of empirical experience of a certain culture; it forms the basis for symbiosis of cultures, an intrusion of one actuality into another, that is evoking the generation of a new actuality. One would argue, what might be so "mind-boggling" in it? However, if the idea of ancillarity of alternative definitions has seemed so far remarkably complicated, then through complimentarity we face things over-complicated, lying beyond the limits of gnoseologically interpreted interaction with its reflection effect (Klochko, 2005). Here the 
matter concerns ontology of interaction, its selectivity and directedness; relation included in the core of an act of interaction comes as a prerequisite, which provides the possibility of interaction and thus has a generative effect. This may pave the way to cognition of the very essence of selfdevelopment, to explication of the mechanisms of complexity growth in system organization as a means of stable existence of open systems.

Thus, only one letter brings in a world of difference between the concepts of "complementarity" and "complimentarity". Each concept, though, signifies an epoch in the development of scientific thought while distance between them constitutes a tendency to regular complexity growth in scientific thinking. The most peculiar is the fact that if "complementarity" concept (and its analogues) was introduced into humanitarian and socio-economic sciences from natural sciences, the concept of "complimentarity" seems to travel in the opposite direction - from humanitarian fields of study to natural-scientific ones. To take Runet as an example, five years ago the frequency of use for these two associated concepts and their analogues in different publications was the matter of a thousand works, today we can hardly estimate the number of studies, both natural and humanitarian, embracing almost all sciences.

What does it manifest? It may indicate that different modes of thinking, if unconsciously, come to accept that divergence of their intrinsic logical systems does not exclude, but, on the contrary, implies a common ground of their origin, a certain triggering, first-begotten rise. In any case, today hardly any science can continue to ignore selectivity and directedness of interaction, which reveals itself among the objects of their specific research. We read about complementary (and complimentary) interactions of nucleotides in DNA molecules in molecular genetics, but ethnologists, economists, chemists, or linguists consider similar interactions. However, until now little attention has been paid to what is meant by the fact that the same concepts are being used in different sciences and what universals of the world they may signify.

The principle of selectivity and directedness of interaction represents a theoretical-methodological foundation of the idea that the Universe, absorbing all kinds of systems, including the living ones, has a common semantic basis. In other words, different levels of matter organization, representing semantic structures of various complexity, employ the same principle of meaning-making due to which the Universe ensures its sustainability as a developing phenomenon. 
A certain misunderstanding still occurs, when a physicist may address a psychologist with the question of selective brain functioning (formulating it explicitly in the binary logic) to receive an answer formulated in the multidimensional logic. It is rather difficult to explain to a physicist, a mathematician, or physiologist that brain does not process the entire volume of information received through receptors; that only what makes sense and value gets processed; that it may not be whatsoever the matter of brain, since even creatures without brain may cope with the task of selecting significant information, as their life space is represented by their own, if more primitive, but semantically shaped reality. We are sure that scholars of various sciences will succeed in a better dialogue if they agree that it is the original semantics of the Universe, which lies behind all these concepts and formulas they operate with.

\section{The Principle of Generative Effect of Selective Interaction}

In his day A. Einstein called a "grand" one the idea of M. Faraday that a charged particle by the very fact of its existence generates a change in the state of space within its immediate proximity (electric field). However, no less astounding seems the idea of L.S. Vygotsky who thought that a positive role of psyche is not that of reality reflection, but in "subjective distortion of actuality in favour of an organism” (Vygotsky, 1982). Subjectively distorted actuality is real but pretersensual: psychologists are not used to dealing with pretersensual qualities of objects, so for quite a long time this idea of L.S. Vygotsky was ignored.

Today the situation is changing. Gradually, psychological thinking becomes not just complex, but over-complex (multidimensional) (Galazhinskiy \& Klochko, 2010). Psychologists have invested enormous efforts trying to force their way to "fields of meanings" (L.S. Vygotsky), "living spaces" (K. Lewin), "personal spaces" (K. Jaspers), "life-worlds" (L. Binswanger, F.E. Vasil'uk), "transsubjective spaces” (D.N. Uznadze), "multidimensional world of an individual" (A.N. Leont'ev), "multidimensional space of life" (V.Y. Klochko).

It can be proved that behind these concepts stands a common radical, though not yet quite recognized, but gradually surfacing, while psychological thinking matures taking more complex forms. It is easy to notice that any developed theory approaches multidimensional spaces, 
which existence cannot be described within the logic of only the objective or the subjective, external or internal, material or mental. It is more difficult to realize that behind these processes there exist objective tendencies of science development and a growing ability of science to handle multidimensional objects. Herewith the process itself remains so insufficiently reflected, that scientific consideration of new logical principles (over-complexity, multidimensionality) still remains in the shadow of subsisting scientific practice, to a large extent based on binary logic.

Cultural-historical psychology pioneered the branch of theories delving into the mechanism of generation of dynamic fields of meanings in which the life of a person unfolds. Strange as it may seem, but the idea of L.S. Vygotsky of a "positive role" of psyche has not yet been recognized (or received any kind of consideration). He believed that a "positive role of psyche" lies not just in reality reflection, but in its distortion in a manner, which lets an individual act consciously, that is, understand the meaning and value of actions. However, it is not altogether surprising: this idea was far ahead of its time. Even today many psychologists would find it rather "mind-boggling" that psyche and consciousness are not identical to a reflection of the world but their functional meaning lies in a particular "distortion" of actuality, which is equal to generation of a multidimensional reality, "doubled" reality not reduced to any of its generative poles. This generative interaction of an individual with the world forms pretersensual dimensions of objects, constituting an "external field" of existence, a field inalienable from an individual but embraced in his identification as a holistic phenomenon.

L.S. Vygotsky poses a question: "Is the commodity, meaning pretersensual thing (Marx), possible without psyche?" Seventy years later modern philosophers elaborating the problem of multidimensionality of social existence would mark the complexities of exposure into logic of multidimensional thinking. They would particularly single out the point of a long-ranged action, which from a philosophical perspective "has not yet been properly considered and set", and a closely correlated ability of science to single out pretersensual objects and work with them (Kemerov, 2000). Scientists argue that philosophy being obsessed with criticism of stereotypes of classical thought and rationality had little time to work out new scientific and philosophical means of identification and description of pretersensual aspects of existence. 
It is essential for our analysis to take into consideration that any one-dimensional representation of human activity cannot be a sufficient characteristics of pretersensual aspects of objects existence, even more so people. V.E. Kemerov maintains that when "human objects" fall into a streamline of activity they reveal their multidimensionality getting involved into a life process of a developing personality of a child or an adult. The term "pretersensual" implies the process and arrangement of human active forces uncoiling in space and time.

What ensues from multidimensional logic seems to be even more complicated. We mean, in particular, recognition of the fact that conscious and spiritual are manifestations of pretersensual complexity of human being interpreted in its continuity. Activity is a means to reveal a person's relation towards the world and oneself while the "essence of psyche from its positive side is... intentional attitude towards an object" - as it was noted by L.S. Vygotsky (Vygotsky, 1986). The question still remains of how intentional relation of a person is transposed, projected onto objects and phenomena of the external world turning them into multidimensional "human objects" which meet expectations, intentions, needs and abilities of a person? This is the very question, to which L.S. Vygotsky, due to his untimely death, left no answer. He was in constant search, though, for "psychological features of the external" through which an individual acquires an ability to influence oneself, "to master oneself” (Vygotsky, 1982). But these pretersensual (psychological) qualities of objects were still to be approached, which required an incredibly complex development: we had to introduce a relation into reflection, to join "two sides of a single characteristics of consciousness. One side of it is processual, another one - is phenomenal, meaning-related and objectrelated" (Leont'ev, 1994, p. 36). From the viewpoint of modern psychology it can be concluded that the very task was accurately formulated, but has never been solved.

The crisis of cultural-historical theory occurred because the means of system analysis were not adequately developed at the time. Nowadays, the analysis of diary notes left by L.S. Vygotsky reveals that he managed to trace what he called "a mistake of our analysis", particularly, he noted that the mistake was in separate examination of the external field and the field of meanings; he realized that such "parallelism" disturbs their unity: "one has to take a single plane" and approach the "streaming dynamics" of life", "dynamics of a flussig kind" (Zavershneva, 2008). How 
should one combine the field of meanings and the external field in a single plane? How do these two fields co-exist in reality? Essentially, this is an approach to really existing multidimensionality of a person's space of life that can be revealed only by means of a particular system-based analysis. L.S. Vygotsky traced yet another mistake in his reasoning: crisis of a theory lies not in the lack of facts, but "inconsistence" of the theory: "we introduced a system-based point of view but too late. Now I understand this in a more profound way" (Zavershneva, 2008, p. 132).

Multidimensional thinking could not just enter psychology: it had to grow mature in it. The process of emergence of professional-psychological thinking, its evolution to higher levels of complexity deserves a special analysis, since the matter concerns not only the degree of maturity of science to put forward tasks of advanced complexity, but also offer solutions.

\section{Paradigmal Dynamics of Science: Ascending to Multidimensionality}

The concept of "paradigm" appeared at the stage of epistemology development when it had learned to consider science as a "self-regulating mechanism" (T. Kuhn), that is, when it tried to imagine itself as a self-regulating system with its own inner sources of development. But, as epistemologists prove, study of such systems is a prerogative of nonclassical science (Stepin, 2005). If we consider science as an open selfdeveloping system (the very consideration which lies in competence of post-non-classical thinking), there surfaces an altogether different picture of nature, mechanisms and tendencies of science development.

If we agree that paradigm is a set of cognitive means, resources and procedures defining a particular "format" of thinking, adequate to a given historical period in science development, then a succession of consequently replaced formats comes to designate the concept of "paradigmal dynamics". It means that it is not the change of paradigm which causes changes in thinking, but on the contrary, a change in scientific thinking (in growing complexity) with the help of the concept of "paradigm" declares a new stage in its development.

Behind the forms (paradigms) we can discern the process of arising of these forms in their involvement in objective tendencies of evolution of science as an open self-developing (and self-organizing) system. 
It is known that such systems exist in a constantly growing complexity of their organization. Self-development cannot be understood without accepting self-organization as its mechanism. In a broader sense selforganization is an inherent ability of the matter to develop its elements into more complicated units and create better-ordered structures in the process of its evolution. It is important that the effect of self-organization is revealed at all the levels of complexity and arrangement, from the macro-world to large scaled structures of the Universe.

Open systems, such as an individual or science, live because of continuous exchange with environment in the process of on-going interaction between them. As it was demonstrated above, such interaction is selective, directed and possesses a generative effect: open systems are able to project onto environment their current states and deficits to select within it something that has a direct relation to a system, that is, has a meaning. Meanings are products of self-organization, but such outcomes that indicate a direction in which a system can focus its efforts. Intentionality, thus, is not a quality inherent exclusively to an individual. All open systems, if each in a different way, "can" distort environment to detect in it something which is urgent for a system at a current moment. That is why development comes as a way of existence of such systems.

It can be assumed that the epicenter of an issue field of modern psychology is determined by peculiarities of its changes within the transition from binary thinking to multidimensional one. The difficulty is that there indiscriminately co-exist elements of simple (one-dimensional-binary) thinking, peculiar to classical habit of thought, complex (binary-ternary) thinking of a non-classical level, and over-complex (multidimensional) thinking, adequate in realities of the emerging post-non-classical epoch. To differentiate them accordingly it is necessary to objectivate the indicators of paradigmal dynamics.

The question of relation through the prism of one-dimensional-binary logic of classical science. At first stages of establishing psychology as a science there did not emerge any particular paradoxes connected with the dyad "reflection-relation". Acquiring its scientific status, trying it on, psychology used the simplest (one-dimensional) logic. At the time to study consciousness meant to study the content of consciousness - to single out its elements through analysis, to structure them to a certain extent and systematize mental phenomena available for introspection. It was 
intuitively clear, that elements of the world, which become available for consciousness, should have a direct relation to a person. So, the question is how relation has turned out to be a guide of objects into consciousness meaningful for a person. But this question did not arise as the one to which a scientific answer can be received.

Involuntary, consciousness as such becomes the subject of relation, it "works", selects stimuli, puts forward hypothesis etc. As it was assumed at the time, relation of an individual to the world, the very vital ontology, determining the logic of life were not taken into consideration, since they would blot out the mechanisms of work of consciousness and its own logic, in coordination with which consciousness "acts". One of the paradoxes of the epoch of the binary logic (in the beginning of the XX century) was the paradox of "doubled reflection". If a person did not reflect "a certain fact of objective reality" then one cannot relate to it. Since one cannot relate to something that has not yet been reflected, represented in consciousness. But if a certain fact has been reflected, then to represent it in one's consciousness an individual has to interact again, though this time an individual interacts with one's personal relation to the fact which exists in the form of one's image or notion about it.

It is interesting that in any variants of binary logic this paradox is reproduced time and again trumpeting the urgency of change in the mode of thinking, to follow a different logic in which this paradox does not occur. This similarly concerns other paradoxes generated by the binary logic if one starts not from consciousness "which selects", but from the notion that "the objects select us". For example, the notion that objects and phenomena of our world stick to us ("are imposed on us") is still rather popular. As a matter of principle, eventually this is the way it is. However, this effect requires an explanation, not just attributing to things and objects an ability to appear as subjects of intentions addressed to us.

Moreover, there surfaces another problem requiring for its solution an exposure into multidimensional logic. The matter is that objects are essentially the outcome of our categorization of reality and this fact has to be taken into consideration. As it turns out, something is being "imposed on our mind", something originating not in the world of "pure" objective reality, but in some other reality, organized in a more complex way. If we deny it, then we are left with the only option suggested 
by $\mathrm{H}$. von Helmholtz, so we could once again assign such features as ability for categorization and meaning-bearing to sensory organs, to the perception itself. Or, if we recognized illogicality of such attribution, we could treat these features as inborn categories - but that won't make the binary logic more coherent. This is how the binary thinking gets stuck between the two oppositions. On the one hand, an individual perceives something he needs (hence, it is not what it really is), on the other hand, an individual perceives what exists in reality (though he might not need that).

The question of relation in the prism of binary-ternary logic of nonclassical science. The essence of non-classical psychology cannot be represented through a set of principles, attributes or theory descriptions. Non-classics is a copious layer of psychology permeated with a tendency of science transition from binary to ternary mode of thinking. It also contains earlier approaches to multidimensional thinking, which have not yet been esteemed. The ternary logic is not the logic simply taking into consideration a certain "third party", located "between" the two adversarial realities. Ternary logic tries to define a new form into which the opposing realities transform during the process of interaction. It starts to view the psyche as something that penetrates the world and transposes into it the complete system of relations of a person with the world and with one's own self. Thus, ternary logic reanimates the Spirit, which now manifests itself as a "totality of all meaningful significances, life directions, acts of emanation from oneself (without alienating from I)" (Bakhtin, 1996).

Let us pay attention to the concepts through which scientists determine this fact of 'insertion' of the Spirit into the surrounding world. These are rather eloquent. Behind the concepts lies a profound comprehension of a most intricate arrangement of a person and the degree of immersion into the depth to the extent to which the logic of professional thinking allowing to step aside from the discreet understanding of the psyche and consciousness (as self-acting in a person well-structured "organs"). Continual logic is mastered slowly, gradually, but it brings the science back to a holistic person, to a person understood in a system way not as to a hypodermic creature extended into the world and to the psyche which plays the most essential role in the generation of multidimensional reality - continuous and dynamic space of life. 
Let us single out certain concepts by which different scientists defined the process of insertion of the spirit into the matter, external into internal, subjective into objective. Having represented a series of such concepts as "co-presence", "co-being", "encounter", "contact", "rootedness", "unity", "organic integrity", " a transitive form", "the trans-subjective", "interconversion", "a new reality", one can intuitively discern a tendency gradually integrating these concepts into a more systemic apprehension of how the encounter of the Matter with the Spirit occurs and what it comes down to in the end.

To take an example, the concepts of "co-presence", "co-being" or "contact" express a less intimate degree of connection between the interacting sides, compared with their "interconversion" which generates "a new reality". This tendency manifests the growth of complexity of cognitive procedures in the process of science development, increase in the level of consistency of psychological thinking. All this occurs within the framework of one stage of science development - the "non-classical" period - and it does not coincide with the timeline of the way traveled. G. Allport may well be right asserting that stability cannot stand as a criterion of "normality" of any evolutionary process, and complexity growth occurs not as a result of homeostasis, it is a consequent of a particular kind of "transistasis" - maintenance of human relationships in dynamics (Allport, 2002).

One of the basic concepts of V. Frankl is the co-existence of a spiritual creation to any other creation. In his search to define this concept he comes to a conclusion: co-presence is "intentionality of this spiritual creation" (Frankl, 1990). Ontology of cognition, as Frankl regarded it, cannot reveal the essence of co-presence - spiritual creation "in a way" co-exists with another creation; we should accept the fact avoiding the question of "how in particular" the spiritual creation co-exists with another creation. It is clear, though, that science will hardly resist the temptation to find an answer to this question.

S.L. Frank tries to reveal the process of insertion of the Spirit into the objective reality: encounter - contact - rootedness - organic integrity. Now science is to comprehend the "organic integrity" of the two beginnings, to initiate a transfer from ternary thinking accepting "the unity" to multidimensional thinking that endeavors to discern a certain internal order in its existence (Frank, 1997). 
D.N. Uznadze offered his conception of interconnection between the internal and the external associated with the "principle of coincidence"; the latter has not yet become an object of special psychological analysis. Why is it so? From our point of view, like L.S. Vygotsky, he came to approach multidimensionality before the time was ripe for such ideas. D.N. Uznadze, in fact, comes close to the idea of selective interaction. He believes that interaction of the internal and the external cannot be regarded as an "random encounter of two kinds of phenomena". Moreover, D.N. Uznadze discovers a source of self-development: he assumes that the internal potentially contains in itself a power, which is released from the state of "simple potentiality" the moment it encounters external conditions, which are "implied by this power". That is why "development implies gradual movement, growth. Hence, the concept of development contains an idea of rule, regularity; random encounter of two kinds of phenomena, undoubtedly, cannot create a regular process" (Uznadze, 2000).

Thus, paradigmal dynamics reveals some conventionality in the attempts to differentiate paradigms by identification of one-dimensional, binary, ternary, and multidimensional modes of thinking, or by demarcation of classical, non-classical and post-non-classical science. Forms of thought corresponding to a higher-level paradigm are born within one paradigm; the features and attributes of ternary or even multidimensional logic are discovered within binary logic. Nevertheless, one can fathom the state of modern science, in which there co-exist diverse forms of professional-psychological thinking. They interact between each other, and this interaction generates a locus of tension, which we define as a transfer to multidimensional thinking.

\section{System Anthropological Psychology as an Example of Implementation of Multidimensional Thinking}

From the perspective of SAP an individual is a unique living system able to produce into the world not only deficits (needs), but also abilities. It is reflected through one's inherent ability for self-realization of one's potential, its building-up in the process of life, no matter how we call this potential - creative, intellectual, personal, human etc. Let us consider peculiarities of this exchange. As long as one is alive, one does 
not merge into environment maintaining one's otherness, but as soon as a person isolates himself or herself from the environment the life ends. This strange symbiosis is, in sober sense, a drama of a person, the core of which is in openness of an individual to the world, his or her extension into it with the feeling of otherness against the background.

For example, in psychology the question of what disappears when a person is being "decomposed" into constituent parts has not yet been addressed. What is going to be lost for even in such decomposition and what can be gained when professional psychological thinking comes to understand the objective complexity of an individual as a holistic (system-based) self-developing and self-organizing multidimensional phenomenon? We can answer these questions briefly but figuratively: the scalpel of analytics kills the Spirit.

It is the Spirit that comes as an envoy of a holistic person in the surrounding world. It turns impersonal, indifferent "surrounding environment" existing in itself and for its own self into a multidimensional animated space of life, in which a person is able to act taking grasp of the meaning and value of one's actions, that is, act consciously and therefore responsibly. The Spirit is a transmitter of human expectations, hopes, demands, needs and opportunities, that is, the set of everything that lies in the basis of the system relations of an individual with the world, into the "indifferent" towards him/her environment. This transmission turns "the thing in itself" into "the thing for us" providing for a person a feeling of reality of his existence. It makes "correlate" the things, which in the system "I" - "not-I" are manifested as "opposites".

What is the Spirit, after all, what is its "psychological portrait"? The Spirit is a description of the psychic taken in its steadiness and continuity, in a long-ranged action, that is in its ability to generate reality of human existence by transposition of human relations into surrounding environment making something which can meet its demands to resonate in return. This conclusion, however, is not the work of a speculative mind. We were to declare meanings and values as pretersensual qualities of objects, when the instrumental recording of emotions synchronized with the ongoing activity of a subject revealed an unexpected and almost inexplicable at that time phenomenon: a continuous response of objective activity conditions to changing subjective human expectations and demands (Klochko, 1991). Conceptions about pretersensual qualities 
were specified in the course of elaborating the principle of system determination, according to which the internal and the external, the subjective and the objective, being involved into interaction, generate something third, that is, pretersensual, system-wide features. As psychological new formations that cannot be reduced to neither of the two, they become a kind of a rank parameter, which shows the directions of system development beyond its actual state and organizes through that the transfer of an opportunity into reality as a foundation for sustainable existence of self-developing systems in real time and space (Klochko, Galazhinskiy 1999; Galazhinskiy, 2002).

Development of system anthropological psychology regards an individual as a self-developing system open towards the world and one's own self. As it seems, however, it does not disgrace a person, does not belittle one's eminence, on the contrary, it brings back and legitimizes the Spirit, expelled from psychology in the course of the twentieth century. In other words, when we are trying to understand the role and mission of the psychic in the system of a holistic person, the Spirit restores its rights. There is no reduction of an individual to primitive systems studied by other sciences. We are trying to consider a person as an over-complex phenomenon requiring for its cognition an adequate complexity in the type of thinking; it is safe to say, that this is the most sophisticated thinking for the "current moment" of actual state of psychology as a science. One has to take into consideration that "today cognitive and technological exploration of complex self-developing systems comes to dictate a strategy of the forefront of science and technological development" (Stepin, 1995).

Here it is necessary to mention that, as we believe, a particular science (psychology) must not pretend to consider the questions that admittedly exceed the limits of its competence. Psychology regards a "holistic person" to solve its particular tasks because, as L.S. Vygotsky pointed out, "without a person as a unity one cannot explain the activity of the instrument (brain); that a person operates the brain, not vice versa (socio!); that without a person it is not possible to understand one's behaviour; that psychology cannot be shaped in the concepts of process, but those of drama" (Vygotsky, 1986). Consequently, we do not suggest that psychology as a science pretends to receive the only correct and most complete knowledge about an individual, encroaching the realm of philosophy or any other humanitarian science. One may believe that psychology today 
needs a "holistic person" because science is trying to assimilate a new paradigm, a new habit of thinking affirming unproductiveness of further attempts to comprehend the role, mission and functions of the psychic in the process of studying itself.

There still remains a principal question of what questions does the science applying multidimensional thinking allow to pose and resolve. Above all, this is the question of selectivity and sensibility of consciousness of a person; the question of dependence of these qualities of consciousness on the organization of a person's life world. A new understanding of ontogenesis regards it as a consecutive acquisition by a person's world of new, higher dimensions (meanings responsible for the objectiveness of the world, meanings providing the feeling of reality of being, values stabilizing space-time evolvement of human being). It also involves a solution to the problem of determination and directedness of the norm-creating activity, including innovating activity (Galazhinskiy \& Klochko, 2010).

\section{References}

Allport, G. (2002). Stanovlenie lichnosti: Izbrannye trudy [Personality emergence: selected works]. Moscow: Smysl.

Bakhtin, M.M. (1996). Sobranie sochineniy [Collected works], vol. 4. Moscow: Yaziki Slavyanskih kultur.

Bibler, V.S. (1991). Ot naukoucheniya - k logike kultury. Dva filosofskih vvedeniya $v$ dvadzat' pervyi vek [From Studies on Science to Logic of Culture. Two philosophical introductions into the twenty-first century]. Moscow: Poltizdat.

Vygotsky, L.S. (1982). Sobranie sochineniy [Collected works], vol. 1. Moscow: Pedagogika.

Vygotsky, L.S. (1986). Konkretnaya psihologiya cheloveka [Concrete psychology of an individual]. Vestnik Moskovskogo Universiteta [Moscow University Bulletin], Ser. 14 - Psychology, 1, 52-65.

Galazhinskiy, E.V. (2002). Sistemnaya determinatsiya samorealizatsii lichnosti [System determination of a personality's self-realization] (Unpublished doctoral dissertation, no. 19.00.01).

Galazhinskiy, E.V., \& Klochko V.Y. (2010). Vysokie gumanitarnye technologii v obrazovanii: mezhdu gumanismom i manipulyatsiey [High humanitarian technologies in education: between humanism and manipulation]. Psyhologiya obuchenija [Psychology of learning], 12, 5-21. 
Zavershneva, E.U. (2008). Zapisnye knizhki, zametki, nauchnye dnevniki L.S. Vigotskogo: rezultaty issledovaniya semeinogo arhiva [Note-books, notes, scientific diaries of L.S. Vygotsky: results of studying the family archive]. Voprosy Psihologii [Psychology Issues], 2, 120-136.

Kemerov, V.E. (2000). Socialnaya filosofiya. Kurs lekzij [Social philosophy. A course of lectures]. Ekaterinburg: Uralskiy State University.

Klochko, V.Y. (1991). Initsializatsija myslitel'noy dejatel'nosti [Initiation of thinking activity] (Unpublished doctoral dissertation, no. 19.00.01).

Klochko, V.Y. (2005). Samoorganizatsija v psihologicheskih sistemah (vvedenie $v$ transspektivnyi analiz [Self-organization in psychological systems (introduction into transspective analysis)]. Tomsk: Tomsk State University.

Klochko, V.Y., \& Galazhinskiy, E. (1999). Samorealizatsiya lichnosti: sistemnyi vzglyad [Personality self-realization: a system look]. Tomsk: Tomsk State University.

Leont'ev, A.N. (1994). Filosofiya psihologii [Philosophy of psychology]. Moscow: Moscow State University.

Stepin, V.S. (2005). Samorazvivayushiesja sistemy i postneklassicheskaja ratsional'nost' [Self-developing systems and post-non-classical rationality] Retrieved from: http://filosof.historic.ru/books/c0026_1.shtml

Uznadze, D.N. (2000). Antologiya gumannoi pedagogiki [Anthology of humane pedagogy]. Moscow: Shalva Amonashvili.

Frank, S.L. (1997). Dusha cheloveka: Opyt vvedeniya v filosofskuju psihologiju [Soul of a person: experience of introduction into philosophical psychology]. Moscow: Respublika.

Frankl, V. (1990). Chelovek v poiskah smysla [Man's search for meaning]. Moscow: Progress. Retrieved from: http://www.gennadij.pavlenko.name/ex-book?text=44 